\title{
CALIBRATING THE COMPENSATION HEAT-PULSE TECHNIQUE FOR MEASURING SAP FLOW IN OLIVE
}

\author{
J.E. Fernández, M.J. Palomo, A. Díaz-Espejo and I.F. Girón \\ Instituto de Recursos Naturales y Agrobiología (CSIC) \\ Avenida de Reina Mercedes 10. Apartado 1052, 41080-Sevilla, Spain
}

Keywords: Olea europaea, sap flow, transpiration, calibration, heat pulse

\section{Abstract}

The compensation heat-pulse method, a technique for measuring sap flow in plants, was calibrated for the olive tree. Two calibration experiments were carried out, the excision and the perfusion experiments. A device was designed in our laboratory for the perfusion experiment, which allowed us to calibrate the technique for a range of $0.5 \mathrm{~L} \mathrm{~h}^{-1}$ to $14 \mathrm{~L} \mathrm{~h}^{-}$ 1. The correction factors given by Green and Clothier (1988) for a $2.0 \mathrm{~mm}$ wound diameter were found to be valid for the olive tree, except when the tree suffered from significant water stress.

\section{Introduction}

The compensation heat-pulse (CHP) method (Green and Clothier, 1988) seems to be one of the most appropriate heat-pulse techniques for measuring sap flow in trees. It has already been used in different species such as apple (Green et al., 1989), pear (Caspari et al., 1993) and kiwi (Green and Clothier, 1995). Moreno et al. (1996) and Fernández et al. (1996) used it for the first time in olive for the determination of sap flows in stem and roots of trees under different water treatments. In the CHP method, a heater probe is inserted radially into the trunk, branch or root in which sap flow is to be measured. The probe releases a pulse of heat as a tracer. The heat-pulse velocity, measured with temperature sensors inserted downstream and upstream the heater probe, is related with the sap flow by Swanson's method (Swanson and Whitfield, 1981; Swanson, 1983). Green and Clothier (1988) showed that Swanson's method cannot be used without a local calibration for plant species, contrary to what had been generally assumed.

In this paper, we show two techniques for calibration of the CHP method in olive trees. Both techniques are based on the ones described by Green and Clothier (1988), though for the perfusion experiment (named laboratory calibration by Green and Clothier), we used a device designed in our laboratory to force known fluxes of a perfusion solution through a trunk section. With this device we are able to force high volumes of solution through trunk sections of olive, despite the small vessel diameter of this species, rarely more than $40 \mu \mathrm{m}$. The two calibration techniques shown here can be used in mature trees of other species, and for a wide range of transpiration rate.

\section{Materials and methods}

The two calibration experiments were carried out in May 1997, on the experimental farm «La Hampa» (Coria del Río, Sevilla) belonging to the Instituto de Recursos Naturales y Agrobiología de Sevilla (IRNASE-CSIC). The CHP system comprised a set of probes and associated electronics connected to a CR 10 Campbell data logger. Each set of probes consists of a linear heater and two temperature sensors. Each temperature sensor has four copper-constantan thermocouple junctions. The two temperature sensors were installed in the trunk asymmetrically about the heater, the downstream sensor at 15 $\mathrm{mm}$ from the heater and the upstream sensor at $5 \mathrm{~mm}$ from it. The thermocouples were 
then at 10,20,30 and $40 \mathrm{~mm}$ below the cambium. The whole system was powered by a 92 A battery.

\subsection{Excision experiment}

On May 8, before dawn, a well-watered 12-year-old Manzanillo olive tree was cut at ground level and the butt placed in a drum with water. The tree was kept in the upright position by a metal support especially built for this purpose. The trunk was recut under water $150 \mathrm{~mm}$ further up the trunk, to eliminate air emboli. While submerged, the butt was placed in another container with distilled water and safranin filtered through $0.45 \mu \mathrm{m}$ membrane. Just about dawn, two sets of CHP sensors were installed, one in the north and another in the south side of the trunk, to monitor sap flow every 30 minutes. Actual transpiration was measured with the same frequency, by refilling the container to maintain water level. The open surface of the container was sealed with vegetable oil to prevent water losses by evaporation. The system was kept running for three days.

\subsection{Perfusion experiment}

A trunk section, $8.8 \mathrm{~cm}$ in diameter and $30 \mathrm{~cm}$ long, of a tree similar to the one used in the excision experiment, was cut on May 17 and attached to a device designed in our laboratory to force known fluxes of a perfusion solution through the trunk section. We used a $50 \mathrm{mM} \mathrm{KCl}$ solution made with distilled water and safranin filtered as in the excision experiment. The device has an aluminium piece to which the trunk section was attached, using epoxy resin and a silicone ring made to fit the size and shape of the trunk. The perfusion solution was pressurised into the aluminium piece by using a bottle of compressed air with a pressure regulator. The solution was made to flow through the stem at different rates by varying the pressure, covering a range of $0.5 \mathrm{~L} \mathrm{~h}^{-1}$ to $14 \mathrm{~L} \mathrm{~h}^{-1}$. The actual flow rate was measured by collecting the solution at the free end of the trunk section. The flow was monitored by CHP sensors installed in the north and south sides of the trunk section.

\subsection{Data analysis}

At the end of each experiment, the trunk was cut at the point where the CHP sensors were installed, to determine the conductive surface of the trunk section, which was coloured by the safranin. A $5 \mathrm{~mm}$ diameter wood sample was also taken with a special auger to determine the wood and water fractions in the trunk. This information was used together with the monitored heat-pulse velocities to calculate the sap flow as described in Green and Clothier (1988). Swanson's model (Swanson and Whitfield, 1981; Swanson, 1983) was used to calculate the correction factors for the heat-pulse velocities, testing different wound diameters - the drill size was $1.8 \mathrm{~mm}$ - and for the mentioned probe spacing. The calculated sap flows were compared with the actual sap flows measured in each experiment.

\section{Results and discussion}

During the excision experiment, the tree transpired very little on the second day after cutting, and a negligible amount (not shown) on the third day (figure 1). This could be due to the clogging of the xylem vessels by phloem exudates. Green and Clothier (1988) describe a procedure to minimise the effect of clogging on the sap flow rate. A good agreement between calculated and actual sap flows was generally observed after applying the correction factors given by Green and Clothier (1988), based on numerical solutions to the heat-pulse technique using Swanson's model (1983), and for a $2.0 \mathrm{~mm}$ wound diameter. In the second half of May 8, however, the agreement between calculated and actual sap flows was very poor. Analysis of the sap velocity profiles at different depths in 
the trunk recorded on that day showed that, during the morning, higher sap flows were recorded in the outer areas of the trunk section, whereas the contrary was observed in the afternoon (data not shown). This difference in the behaviour of sap velocity profiles may be due to a certain level of water stress in the experimental tree. If this is confirmed by future work, it could be assumed that the shape of sap velocity profiles may be used as an indicator of water stress. It would also be clear that the integration process of the sap velocities determined at different radial depths under conditions of water stress will have to be modified to obtain better results.

The average sap flows calculated in the perfusion experiments with the outputs of the north and the south probes agreed quite well with the actual sap flows (figure 2), after using the mentioned correction factors. This indicates that they can be considered valid for the olive tree. This agrees with the findings of Green and Clothier (1988) for apple, which has small, short, closely spaced xylem vessels. Similar characteristics can be observed in the vascular system of the olive tree. Its xylem vessels rarely have a diameter greater than $40 \mu \mathrm{m}$, with distances between vessels less than $200 \mu \mathrm{m}$. In kiwi, however, a species with xylem vessels in the range of 100 to $500 \mu \mathrm{m}$ diameter and distances between vessels from 100 to $800 \mu \mathrm{m}$. Green and Clothier (1988) found that the correction factors given by Swanson's model had to be substantially modified to get a good agreement between actual and calculated sap flow values.

Notable differences in sap flow between the north and south probes were sometimes recorded in both the excision and the perfusion experiments (Figures 1 and 2). These results illustrate the need to install more than one set of probes in the organ in which sap flow is to be measured, particularly if it has a big diameter.

\section{Acknowledgements}

We are grateful to Drs S.R. Green and B.E. Clothier for their help in the analysis of data and interpretation of the results. We acknowledge the Comisión Interministerial de Ciencia y Tecnología of the Spanish Ministry of Education and Science for the financial support of this project. Many thanks to Antonio Ortiz, for his inestimable help in the design and building processes.

\section{$\underline{\text { References }}$}

Caspari, H.W., Green, S.R. and Edwards, W.R.N. 1993. Transpiration of well-watered and water-stressed Asian pear trees as determined by lysimetry, heat-pulse, and estimated by a Penman-Monteith model. Agric. For. Meteorol. 67: 13-27.

Fernández, J.E., Moreno, F., Clothier, B.E. and Green, S.R. 1996. Aplicación de la técnica de compensación de pulso de calor a la medida del flujo de savia en olivo. Comunicaciones al XIV Congreso Nacional de Riegos. Aguadulce (Almería), 11-13 de junio, 1-7 pp.

Green, S.R. and Clothier, B.E. 1988. Water use of kiwifruit vines and apple trees by the heat-pulse technique. J. Exp. Bot. 39: 115-123.

Green, S.R. and Clothier, B.E. 1995. Root water uptake by kiwifruit vines following partial wetting of the root zone. Plant Soil 0: 1-12.

Green, S.R., McNaughton, K.G. and Clothier, B.E. 1989. Observations of night-time water use in kiwifruit vines and apple trees. Agric. For. Meteorol. 48: 251-261.

Moreno, F., Fernández, J.E., Clothier, B.E. and Green, S.R. 1996. Transpiration and root water uptake by olive trees. Plant Soil 184: 85-96.

Swanson, R.H .1983. Numerical and experimental analysis of implanted-probe heatpulse theory. Unpublished Ph.D. Thesis, University of Alberta.

Swanson, R.H. and Whitfield, D.W.A. 1981. A numerical analysis of heat-pulse velocity theory and practice. J. Exp. Bot. 32: 221-239. 


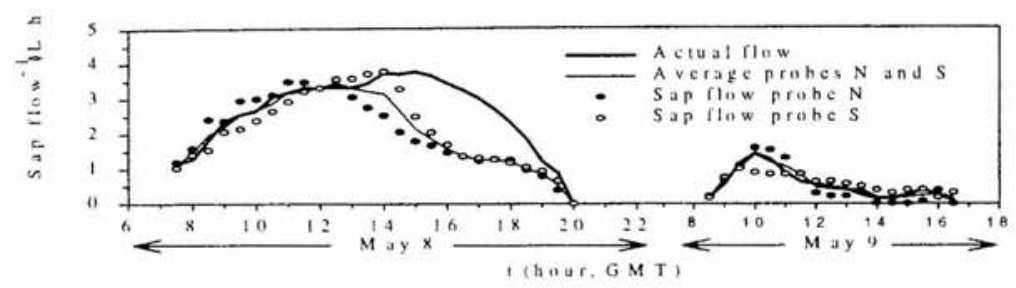

Figure 1. Actual and calculated sap flows from the excision experiment. Calculated sap flows from the north (N) and the south (S) probes are shown, as well as the average of both probes. Data are single measurements every half-hour during two experimental days.

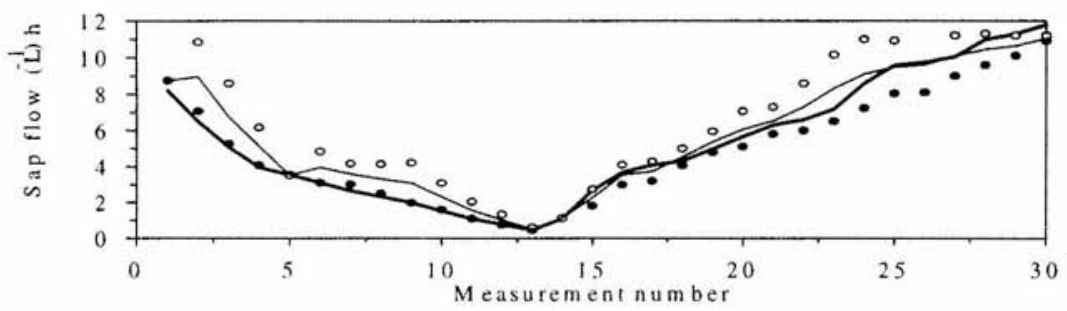

Figure 2. Actual and calculated sap flows from the perfusion experiment. Calculated sap flows from the north $(\mathrm{N})$ and the south $(\mathrm{S})$ probes are shown, as well as the average of both probes. Data are single measurements for different pressures, after reaching stable flow in the trunk section (see text for details, and Figure 1 for definition of symbols). 